To Rur slope ane on the Prine Griacryte

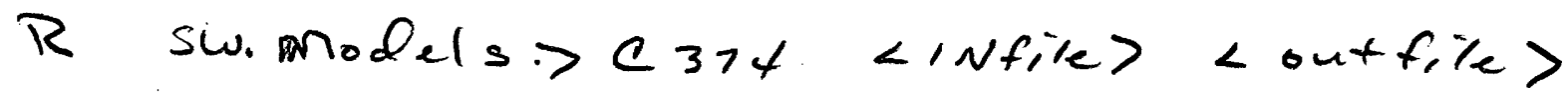

SURFACE WATER TECHNIQUES

Computer Technique for Slope-Area Measurements

\title{
HYDRAULIC MEASUREMENT AND COMPUTATION
}

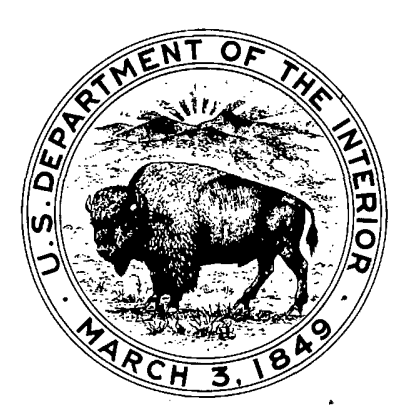

BOOK 1

CHAPTER 15

1965

UNITED STATES DEPARTMENT OF THE INTERIOR GEOLOGICAL SURVEY 
○

○

○ 


\title{
SURFACE WATER TECHNIQUES
}

\author{
Computer Technique for \\ Slope-Area Measurements
}

Book 1 - Hydraulic Measurement and Computation

Chapter 15 - Computer Technique for Slope-Area Measurements 


\section{SURFACE WATER TECHNIQUES SERIES}

Reports in this series that have been issued to date are listed below. An asterisk indicates the report has been published and is for sale by the Superintendent of Documents.

Book 1, Chapter 1, Computation of Water-Surface Profiles in Open Channels, 1964

Book 1, Chapter 1, Supplement No. 1, Backwater at Bridges, 1964

Book 1, Chapter 2, Computation of Discharge in Tidal Reaches, 1964

Book 1, Chapter 8, Computation of Stage-Discharge Relationships at Culverts, 1965

Book 1, Chapter 15, Computer Technique for Slope-Area Measurements, 1965

Book 2, Chapter 1, Storage Analyses for Water Supply, 1964. 


\section{PREFACE}

The primary purpose of "Surface Water Techniques" is to provide members of the Surface Water Branch with information on technical procedures which will assist and guide them in planning and executing specialized work. The material is grouped under four main subject headings, designated as "Books, " as follows:

Book 1. Hydraulic measurement and computation

Book 2. Hydrologic analysis

Book 3. Instruments and equipment

Book 4. Design of investigations

Subject matter is grouped into books and chapters with the chapter being the unit of publication and also of revision. Techniques change from time to time, thus publication by chapters permits ready revision when appropriate. Instructions contained in the chapters as initially released are considered provisional and subject to revision because of experience in use or because of advancement in knowledge, techniques or equipment.

Judgment must be used in deciding how closely to adhere to instructions. Instructions which include information on preparation of data for use in a computer program must be closely followed. Instructions on methods of analysis are generally less binding and are not to be utilized to the extent of inhibiting initiative or stifling progressive development. However, before using a technique which differs substantially from one which has been recommended, it should be discussed with the office of the Branch Chief.

When a technique has been sufficiently developed a new edition will be issued in similar format but in a more permanent form. Publication will be announced in "New publications of the Geological Survey" and the report will be for sale by the superintendent of Documents, but will have no automatic free distribution outside of the Survey. 
-

-

○ 


\section{CONTENTS}

Page

Page

Surface Water Techniques series..... ii

Preface ................... iii

Abstract.................... 1

Introduction. ................ 1

Computer program ............. 1

Procedure................... 2

Field data................ 2

Office computations........... 2

Preparation of data ........... 3

Stream heading card $1 \ldots \ldots \ldots .3$

Cross section parameters

card $2 \ldots \ldots \ldots \ldots \ldots \ldots \ldots . \ldots \ldots$

Base data card $3 \ldots \ldots \ldots \ldots 66$

Subarea coefficients card $4 . \ldots \ldots 6$
Procedure--Continued

Preparation of data--Continued

Discharge-water surface card $5 \ldots \ldots \ldots \ldots \ldots \ldots 6$

Initial water-surface elevation $\mathrm{h}_{\mathrm{i}}$ card $5 \ldots \ldots \ldots \ldots \ldots \ldots \ldots \ldots \ldots \ldots \ldots \ldots \ldots$

Transmittal ................ 7

Computation................ 7

Punch cards .............. 7

Printout.................. 7

Application of program ........... 7

Example.................... 7

References................. 14

\section{ILLUSTRATIONS}

Figure 1. Definition sketch of slope-area reach .................... 3

2. Sketch showing method of assigning water-surface elevations to subareas of a

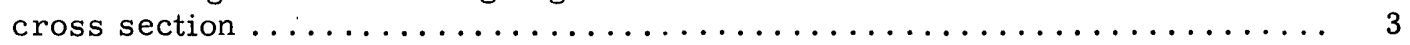

3. Experimental form 4405B-1 adapted without change for computation of discharge measurement by slope-area method ................. 4

4. Experimental form 4405A-1 Rev. 11-6-64 adapted without change for cross section data input, slope-area computation .................. 5

5. Completed data form $4405 \mathrm{~B}-1$, stream heading card $1 \ldots \ldots \ldots \ldots \ldots \ldots \ldots$

6. Completed data form $4405 \mathrm{~A}-1$, cross section $1 \ldots \ldots \ldots \ldots \ldots \ldots \ldots \ldots$

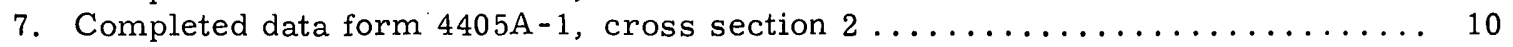

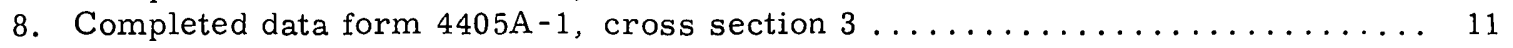

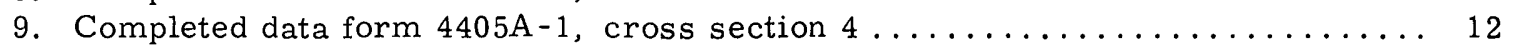

10. Results of computation given on printout sheet, Snake River near Connell,

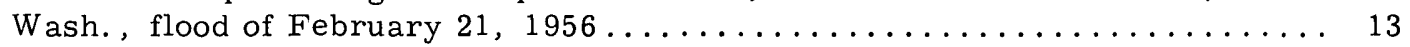


0

0 


\title{
COMPUTER TECHNIQUE FOR SLOPE-AREA MEASUREMENTS
}

\author{
By W. P. Somers and G. I. Selner
}

\section{ABSTRACT}

The report gives detailed instructions on preparation of input data for automatic computation of a discharge measurement by the slope-area method. The program follows standardized methods of computing cross section properties and uses multisection discharge equations. The printout comprises hydraulic properties of each section and computed discharges for each component subreach and for the entire reach. One example demonstrates the technique.

\section{INTRODUCTION}

Procedures for computation of discharge by the slope-area method given by Dalrymple and Benson (1965) have been programed for automatic computation. This program is used to compute the discharge of a single flood event. Input data are ground elevations and stationing to define each cross section, roughness coefficients and water-surface elevations for cross sections, the fall in water surface between cross sections, and the distance downstream from a reference point to each cross section.

The output data are properties of each section and subsection, and the Froude number of the subsection that has the largest conveyance; the discharge computed for each subreach and the entire reach by multisection formula.

This manual gives detailed instructions on preparation of data for automatic computation of discharge and section properties.

\section{COMPUTER PROGRAM}

The program follows closely the procedures given in Surface Water Techniques, Book 1, Chapter 4, "Measurement of Peak Discharge by the Slope-Area Method, "by Tate Dalrymple and M. A. Benson, 1965. The program is designed for the Burroughs 220 Computer.

The program handles up to 15 cross sections. Each cross section can be defined by 3 to 100 points and subdivided into a maximum of 6 subareas. (The terms "subarea" and "subsection" are equivalent.) Each subarea is assigned a roughness coefficient and a water-surface elevation to accommodate a superelevated water-surface. The fall from each section to the next one downstream is given as input data and is determined from analysis of the water-surface profiles as described by Dalrymple and Benson. The assigned fall is independent of the elevations assigned to each subarea.

Results are printed out giving for each cross section and component subareas the following properties: area, top width, wetted perimeter, hydraulic radius (each subarea only), conveyance, and discharge (multisection result). The velocity head coefficient, $\alpha$, and the Froude number for the subarea with the greatest conveyance are given. The computed discharge for each successive subreach is also given. These discharges provide an indication of the internal consistency of the whole computation.

The equations used to compute discharge are given in the following table. 


\begin{tabular}{|c|c|}
\hline $\begin{array}{c}\text { Number of } \\
\text { cross sections }\end{array}$ & Discharge equations \\
\hline Two sections & $\mathrm{Q}=\mathrm{K}_{2} \sqrt{\frac{\mathrm{K}_{2}}{\mathrm{~K}_{1}} \mathrm{~L}+\frac{\mathrm{K}_{2}^{2}}{2 \mathrm{gA}_{2}^{2}}\left[-\alpha_{1}\left(\frac{\mathrm{A}_{2}}{\mathrm{~A}_{1}}\right)^{2}(1-\mathrm{k})+\alpha_{2}(1-\mathrm{k})\right]}$ \\
\hline $\begin{array}{l}\text { Multiple (n) } \\
\text { sections }\end{array}$ & 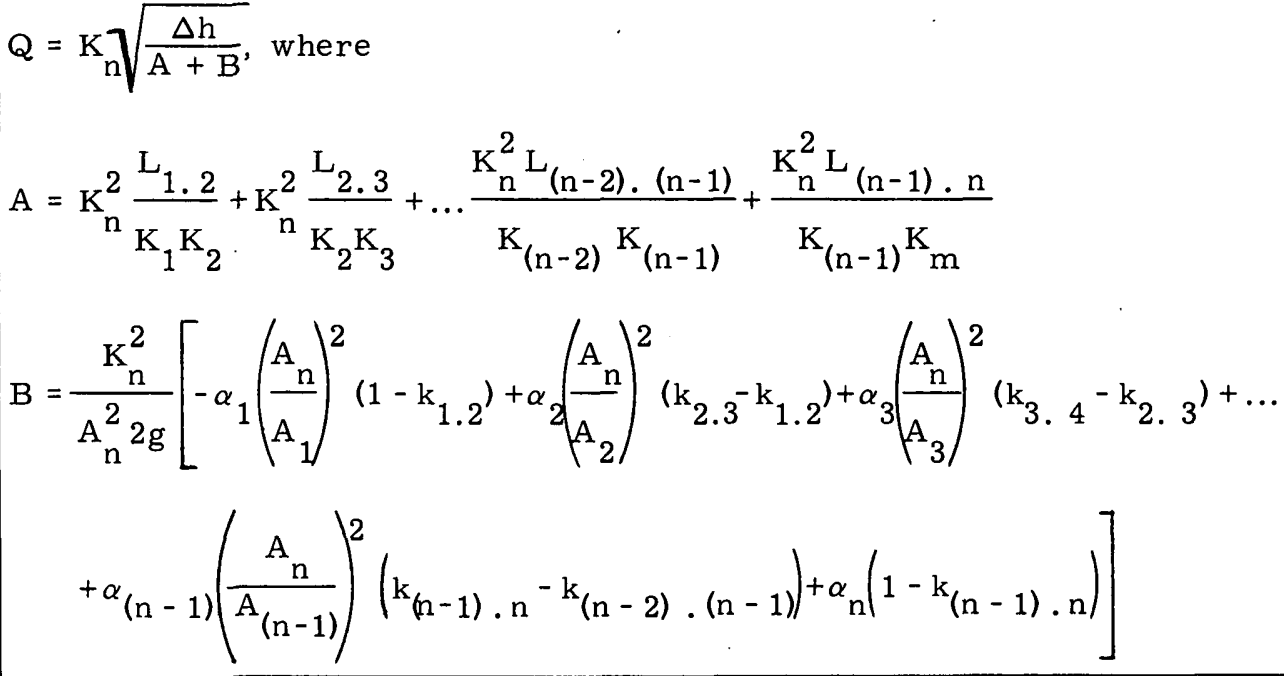 \\
\hline
\end{tabular}

The variables in the equation are:

$\mathrm{Q}=$ discharge

$\mathrm{K}_{1}, \mathrm{~K}_{2}, \mathrm{~K}_{\mathrm{n}}=\begin{gathered}\text { conveyance of specific sections increasing numerically in downstream } \\ \text { direction }\end{gathered}$

$\Delta \mathrm{h}=$ fall in reach between end sections

$L, L_{1.2}, L_{2.3}=$ length of reach or subreach between designated cross sections

$A_{1}, A_{2}, A_{n}=$ area of designated cross section

$\alpha=$ velocity head coefficient

$\mathrm{k}=$ adjustment coefficient for energy conversion. If

$$
\left[\alpha_{2}-\alpha_{1}\left(\mathrm{~A}_{2} / \mathrm{A}_{1}\right)^{2}\right] \text { is } \geq 0, \mathrm{k}=0 \text {; if }<0, \mathrm{k}=0.5 \text {. }
$$

\section{PROCEDURE}

\section{Field Data}

Techniques of collecting field data are unchanged. Obtain adequate plans, profiles, and properly located cross sections, and select roughness coefficients in the field.

\section{Office Computations}

Plot the survey notes to scale reach lengths and analyze the high-water mark profiles. Elements of the reach are defined in figure 1. Plot cross sections showing subdivision and water surface from bank to bank. Use the elevation of the midpoint of the water surface over each subarea for input data. The scheme for varying the water-surface elevation is illustrated in figure 2. Cross section properties, form 9-191, and computation of discharge,form 9-193 need not be used. 


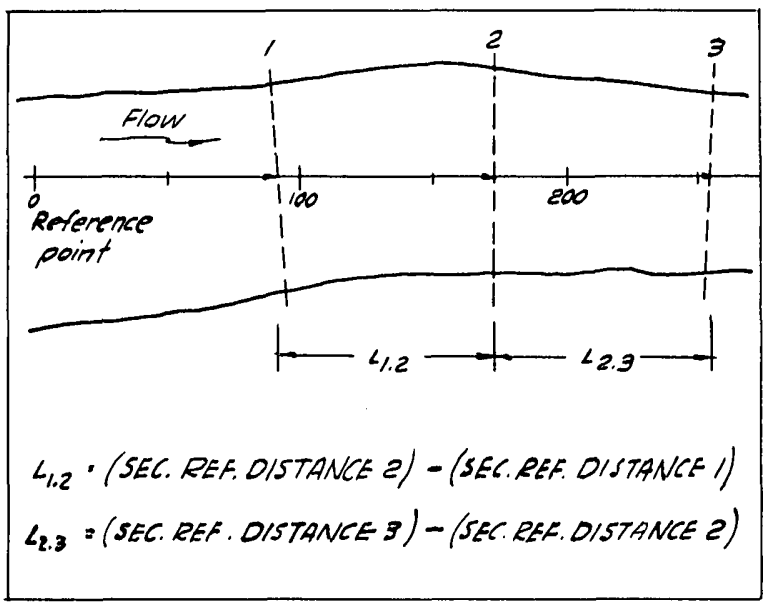

Figure 1.--Definition sketch of slope-area reach.

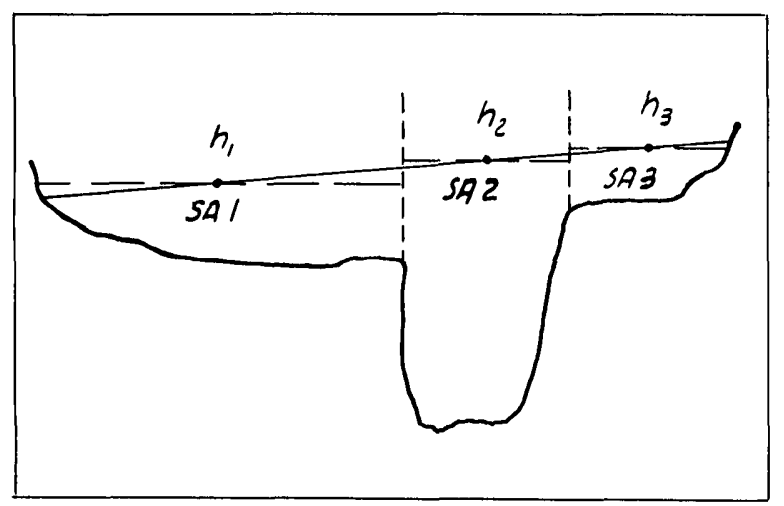

Figure 2. --Sketch showing method of assigning water-surface elevations to subareas of a cross section.

\section{Preparation of Data}

Use Geological Survey Experimental forms 4405A-1 (or 4405A-1 Rev. 11-6-64) and 4405B-1. These forms are used for computation of water-surface profiles in open channels. Because the input data for slopearea computation are basically similar, the same forms have been adapted with no change. Order forms from Hydraulics Sertion, 40425402 , Washington, D.C. 20242. (See figs. 3 and 4 .)

Because of the adaptation, give careful attention to the instructions for filling the form. One form 4405B-1 is used for each measurement computation; one or two forms 4405A-1 are used for each cross section.

\section{Stream Heading Card 1}

Cross out "Backwater Analysis;" write in "Slope-Area Solution for Discharge." The stream heading must always precede the cross section parameter cards. Only three blocks are filled on one form for measurement.

Columns 4-39. --STREAM IDENTIFICATION is any numeric, alphabetic; or mixed information identifying the stream and location.

Columns 45-48. --Total no. cross sections is the number of cross sections in the reach; minimum 2, maximum 15.

Columns 74-78. --SEQ is the sequence number beginning with any integer. Subsequent cards in this reach will have sequence numbers in ascending order, downstream direction.

\section{Cross Section Parameters Card 2}

The instructions for this card apply to each cross section in downstream order.

Columns 3-6. - -SEC ID no. is the cross section identification, either alphabetic, numeric, or mixed.

Columns 8-10. - -no. STA's is the total number of ground elevations on the cross section; minimum 3, maximum 100.

Columns 12-15. - $-h_{0}$ is adapted to be fall in water-surface elevation, $\Delta h$, from the previous section to this section. On the first section leave this value blank. Record $\Delta h$ to hundredths of a foot without showing the decimal and right justifjed. Thus a fall, $\Delta h$, of 1.42 foot would be 142 . No leading zeros are needed. A fall of 1.00 foot would be 100 .

Column 17. --no.SUB. ARS is the number of subareas in the section; minimum 1 (for unit channel, no subdivision), maximum 6 .

Columns 19-25. --SEC. REF. DISTANCE is the distance, in whole feet, from a fixed reference point downstream along the channel to this section. If this section is at the reference point, use 0 , right justified. Be certain to make distances increase in the downstream direction. The minimum distance that can be used is 0 ; maximum is 9999999.

Columns 74-78. --SEQ is the sequence number, right justified. Remember that card 1 is the first sequence number of the series for a measurement computation. 


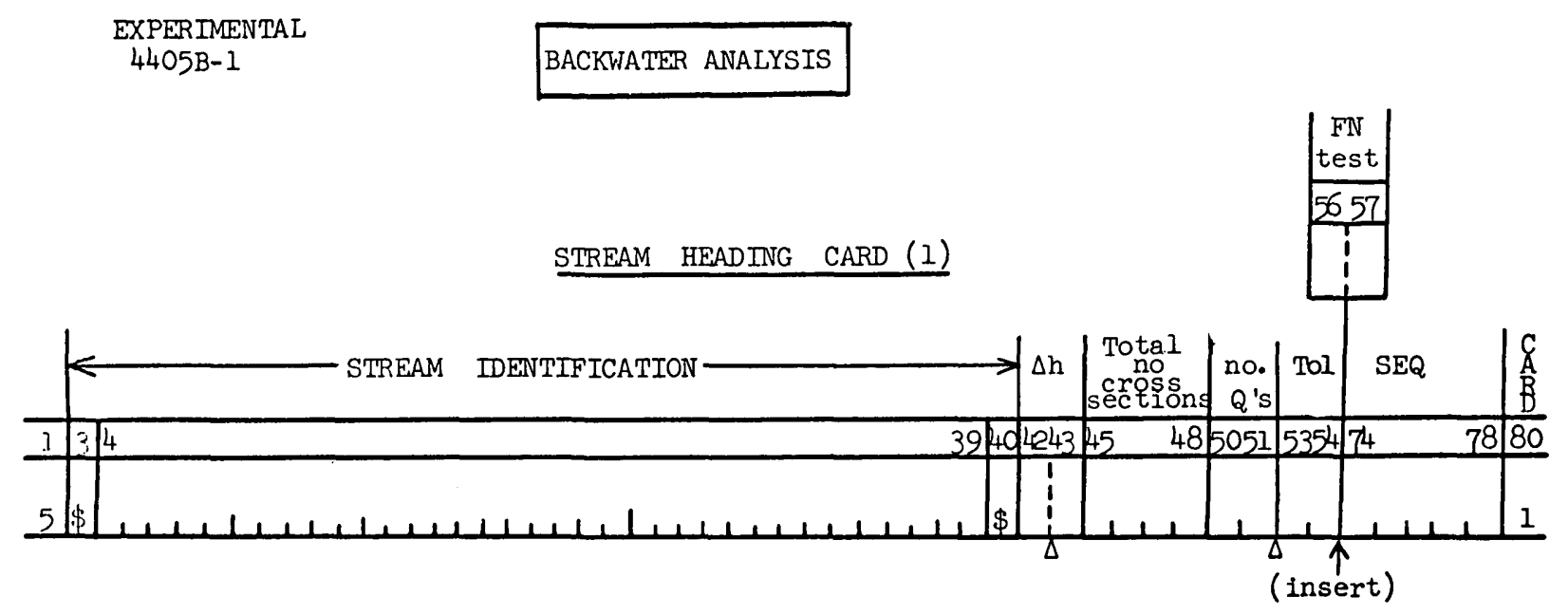

DATA SEQUENCE OUTLTNE

A1l lines recorded must be in numerical sequence, beginning with the sequence number (SEQ) written on the above STREAM HEADING CARD. Card types 2, 3 and 4 must always be included for every cross section. Card 1 is required only at the beginning of the first cross section (starting section). Card 5 is used to introduce discharges at any cross section; card 5 is also used to record the initial discharges and water surface elevations for the starting section.

\begin{tabular}{ccl} 
CARD & TYYPE OF CARD & \multicolumn{1}{c}{ REMARKS } \\
\hline & STREAM HEADING & For entire reach \\
2 & CROSS SECTION PARAMETERS & Each section \\
3 & BASE DATA & Each section \\
4 & SUB-AREA COEFFICIENTS & Each section \\
5 & DISCHARGE - WATER SURFACE & h's at initial section only. Q at initial \\
& & section and section where $Q$ changes.
\end{tabular}

Figure 3. --Experimental form 4405B-1 adapted without change for computation of discharge measurement by slope-area method. 
EXIER IMENTAL

$4405 \mathrm{~A}-1$

Rev.11-6-64

CROSS SECTION PARAMETFRS CARD (2)

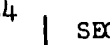

SEC. no.

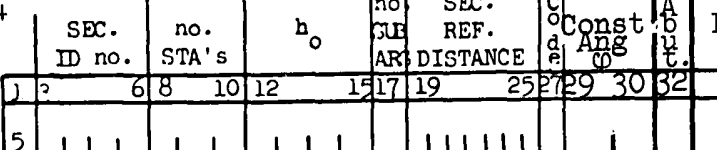

AR DISTANCE e. 0 t.

BACKWATER ANALYSIS $\quad$ SEQ $\| \begin{aligned} & A \\ & R \\ & D\end{aligned}$

*Abutment normal insert 0

Abutment skewed insert 1 BASE DATA CARDS (3)

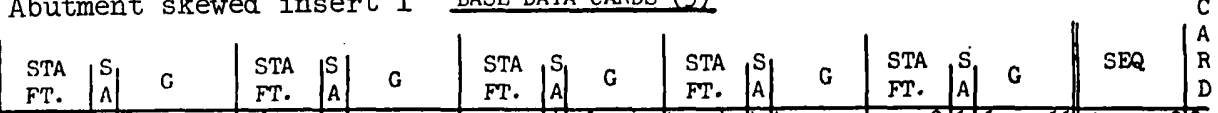

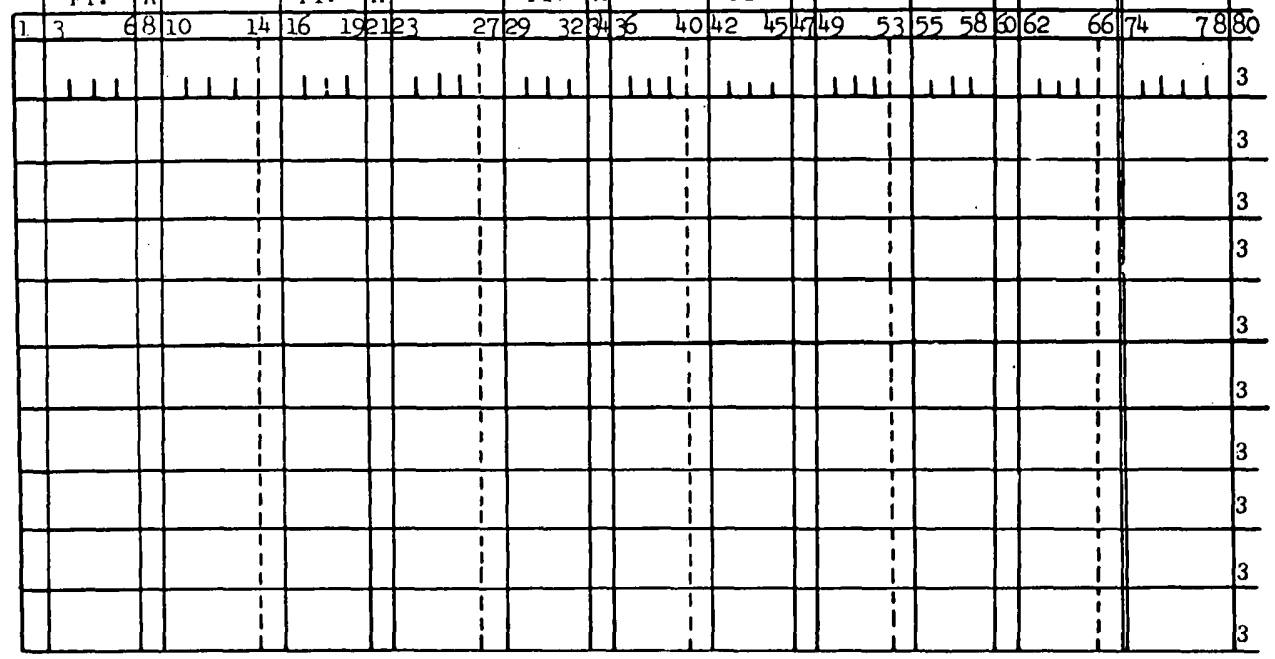

(If more than 50 stations, continue base data on second sheet)

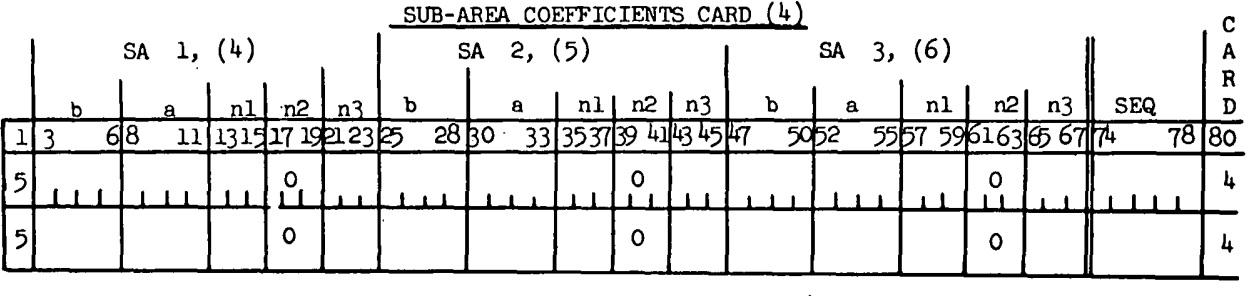

DISCHARGE-WATER SURFACE_CARD (5)

DISCHARGE $Q_{1}$

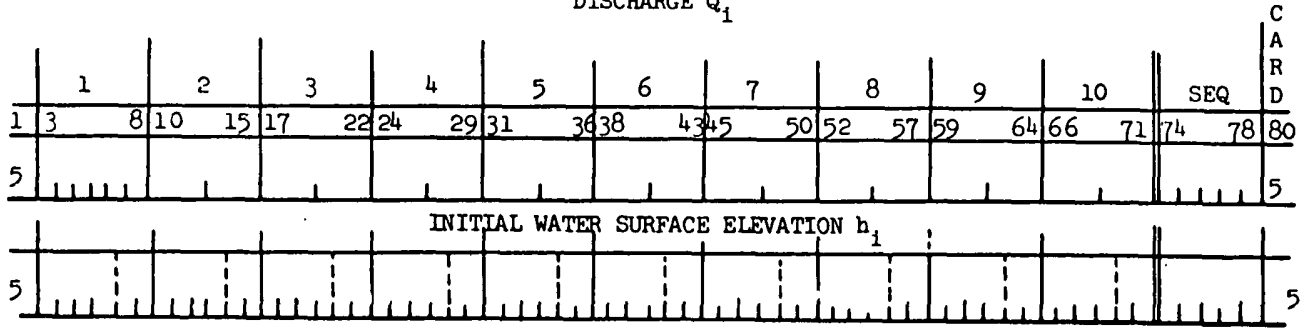

Figure 4. --Experimental form 4405A-1 Rev. 11-6-64 adapted without change for cross section data input, slope-area computation. 
This completes the data required on card 2. Note that columns 27-73 are left blank.

\section{Base Data Card 3}

Each base data card 3 (one line on form 4405A-1) provides space for 5 sets of cross section points. Each set comprises the distance from initial point on the section (STA FT.), subarea identification number (SA), and the ground elevation (G).

The form provides space for 10 card 3 's or 50 sets. If more than 50 sets are required, continue listing the sets on a second sheet. Give each card 3 used a sequence number; carry the sequence to the second sheet continuation, if used. If a second sheet is used, scratch out the 4 lines (cards 4 and 5) on the lower part of the first sheet. Card 5 will be used on the second sheet.

List the STA FT., in whole feet, in ascending positive order, right justified. Negative STA FT. can be used if a minus sign appears in the column preceding the first digit of the number.

Begin numbering the subareas (SA) with the digit 1 corresponding to the first STA FT. Up to 6 subareas can be used in one section. At a subdivision point, use the number corresponding to the new subarea. For example, sets for part of a cross section, subdivided at station 300 between subareas 3 and 4, would appear as:

\begin{tabular}{|c|c|c|c|c|c|c|c|c|}
\hline $\begin{array}{l}\text { STA } \\
\text { FT. }\end{array}$ & $\begin{array}{l}\mathrm{S} \\
\mathrm{A}\end{array}$ & G & $\begin{array}{l}\text { STA } \\
\text { FT. }\end{array}$ & $\begin{array}{l}\mathrm{S} \\
\mathrm{A}\end{array}$ & G & $\begin{array}{l}\text { STA } \\
\text { FT. }\end{array}$ & $\begin{array}{l}\mathrm{S} \\
\mathrm{A}\end{array}$ & G \\
\hline 280 & 3 & 12 & 300 & 4 & $15: 0$ & 310 & & 15 \\
\hline
\end{tabular}

List ground elevations $(G)$ to tenths of a foot always. If elevation is known only to the nearest foot, add a zero for the tenth. The dotted lines in the G columns represent decimal positions. Leading zeros may be left blank; zeros in the column for tenths must always be entered.

The last point of a cross section can fill any set of any card 3. Leave the rest of an incomplete line blank and assign a sequence number to it. Assign sequence numbers only to card 3 's that contain data.

The pattern described below is duplicated for 10 lines on one form 4405A-1: If lacking, add a digit 5 (col. 1) for each card 3 used.

STA FT. (col. 3-6, 16-19, 29-32, 42-45, 55-58); maximum 9999 feet.

SA (col. 8, 21, 34, 47, 60); integer 1-6.

G (col. 10-14, 23-27, 36-40, 49-53, 62-66); maximum 9999. 9 feet.

SEQ (col. 74-78) integer 1-99999.

\section{Subarea Coefficients Card 4}

These two cards are not used in the slope-area program. Simply draw a line through them and do not use a sequence number for either card.

\section{Discharge-Water Surface Card 5}

This card has been adapted so that the heading is unrelated to its use in the slopearea program. Use the first card 5 to list roughness coefficients, $\underline{n}$, for each subarea or a unit channel. Only the first six blocks of 6 columns are used. List the roughness coefficient for a unit channel or the first subarea in the first block using columns 6-8. For example, an $\underline{\mathrm{n}}$ of 0.080 would be listed as $, 0,80$. The decimal is assumed to precede the three digit value, right justified. Fill as many blocks as there are subareas (number in column 17 of card 2). Add the sequence number (one more than the last card 3 sequence number) in columns 74-78, right justified.

\section{Initial Water-Surface Elevation $h_{i}$ Card 5}

This card has been adapted to list the water-surface elevation of each subarea of this cross section. Only the first six blocks of 6 columns are used. The dotted line represents the decimal position. List the water-surface elevation assigned to subarea 1 in the first block using as many columns as required up to six. Leading zeros may be left blank; zeros in the tenths and hundredths columns must always be entered. Fill as many blocks as there are subareas (number in column 17 of card 2). Note that if each subarea has the same water-surface elevation, repeat that elevation for each subarea. Otherwise the computer will use the elevation as 0.00. Add the sequence number in columns $74-78$, right justified. 
Continue preparation of individual forms 4405A-1 for as many cross sections as needed. Maintain continuous sequence numbering from section to section.

This completes the preparation of data.

\section{Transmittal}

Send completed forms to Chief, $\mathrm{Branch}$ of Computations, 1451 Interior Bldg. , Washington, D. C. 20242. Include in the memorandum (1) the title of the program "Slope-Area Solution for Discharge," (2) stream names and locations, (3) special instructions, (4) number of printouts desired, (5) completion date required, (6) office and account to be charged, and (7) return address. Send a copy of the memorandum to W. L. Isherwood, 5247 Interior Bldg.

In the early phases of this program, route the transmittal through Hydraulics Section, 40425402 , Washington, D. C. 20242, for a precomputation check. Address questions on the program and suggestions to the Hydraulics Section.

\section{Computation}

\section{Punch Cards}

The Branch of Computations will transfer data on the forms to punch cards exactly in accordance with the data on the form. No departure from the format can be handled. If an incorrect position is used for a bit of information, no solution or an incorrect solution can result.
Printout

Computed results are given in the printout sheet and carbon copies. Two sections are given: (1) individual 2-section subreach discharges, and (2) multisection discharge and hydraulic properties of each cross section. See the example at the end of this manual for details.

\section{APPLICATION OF PROGRAM}

The printout gives one answer-the discharge computed for the described conditions. The additional information enables study of the results to help appraise the reliability of the measurement. The program would be particularly useful when several slope-area measurements require computation. Following major floods when many indirect measurements are to be computed, all of the slope-area measurements could be computed at once, saving manual computing and checking of section properties, alpha, and discharges. Nevertheless, a single measurement can be computed with worthwhile savings.

\section{EXAMPLE}

An example of computation of a slopearea measurement is given below. The example used in "Measurement of Peak Discharge by the Slope-Area Method, "for the flood of February 21, 1956, Snake Creek, near Connell, Wash., provided the data. Facsimile input data forms are given in figures 5-9. Printout results are given in figure 10. 


\section{SLOPE-AREA SOLUTION FOR DISCHARGE}

EXPERIMENTAL 4405B-1

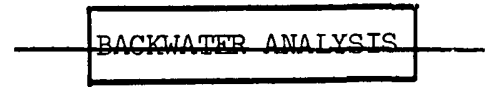

STREAM HEADTNG CARD (1)

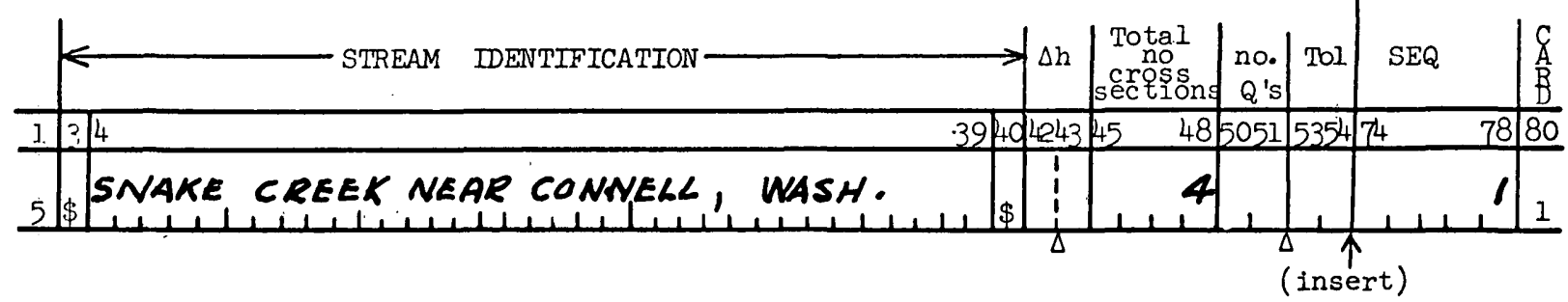

\section{DATA SEQUENTE OUTLINE}

All lines recorded must be in numerical sequence, beginning with the sequence number (SEQ) written on the above STREAM HEADING CARD. Card types 2, 3 and 4 must always be included for every cross section. Card 1 is required only at the beginning of the first cross section (starting section). Card 5 is used to introduce discharges at any cross section; card 5 is also used to record the initial discharges and water surface elevations for the starting section.

$\begin{array}{cc}1 & \text { STREAM HEADING } \\ 2 & \text { CROSS SECTION PARAMETERS } \\ 3 & \text { BASE DATA } \\ 4 & \text { SUB-AREA, COEFFICIENTS } \\ 5 & \text { DISCHARGE - WATER SURFACE }\end{array}$

For entire reach

Each section

Each section

Each section

h's at initial section only. Q at initial section and section where $Q$ changes.

Figure 5. --Completed data form 4405B-1, stream heading card 1. 
EXYRTMENTAL $4405 A-1$

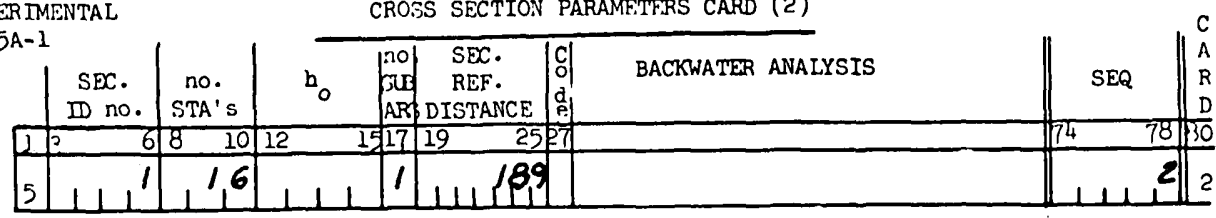

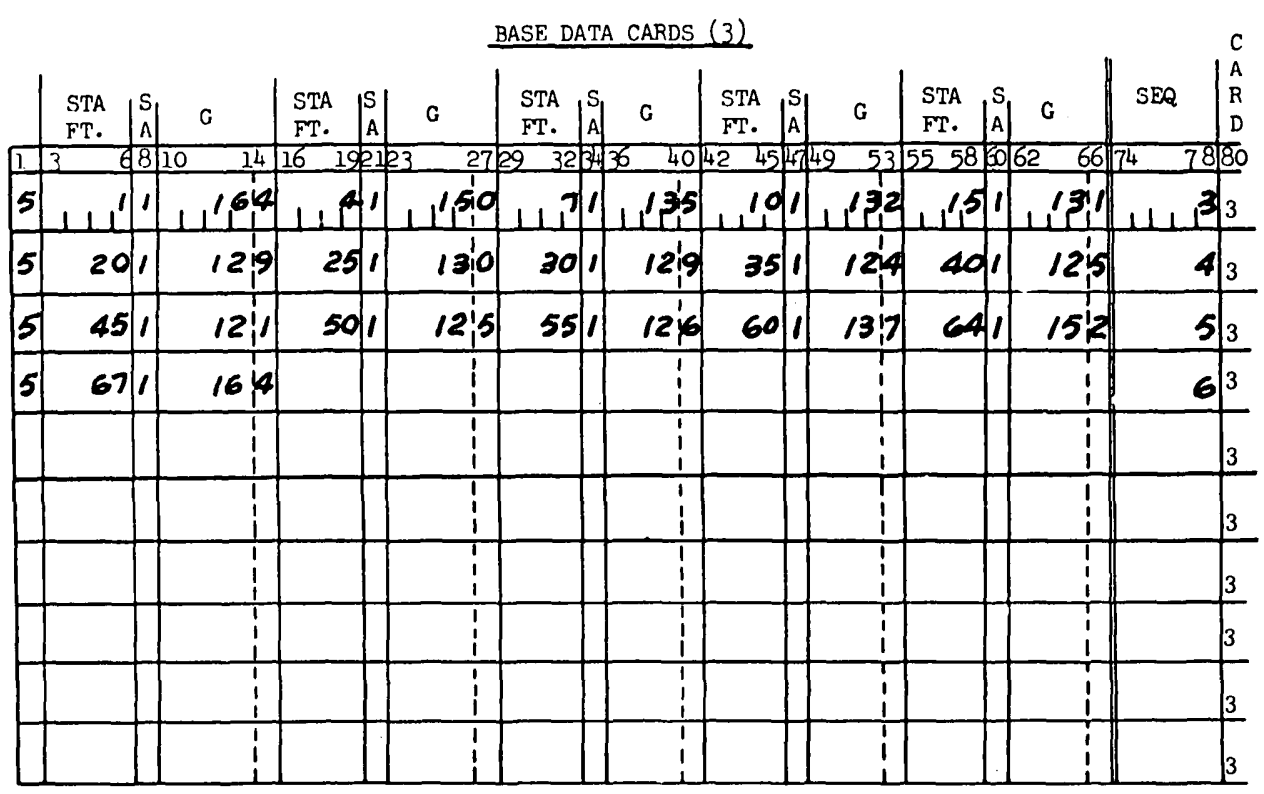

(If more than 50 stations, continue base data on second sheet)

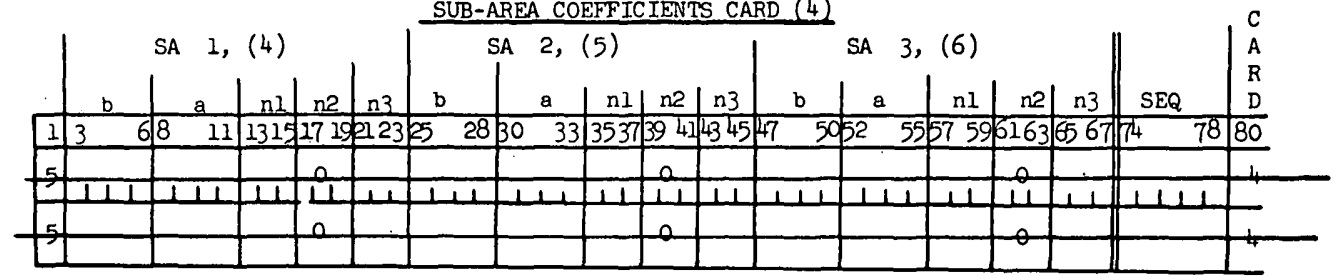

DISCHARGE-WATER SURFACE CARD (5)

$$
\text { DISCHARGE } Q_{1}
$$

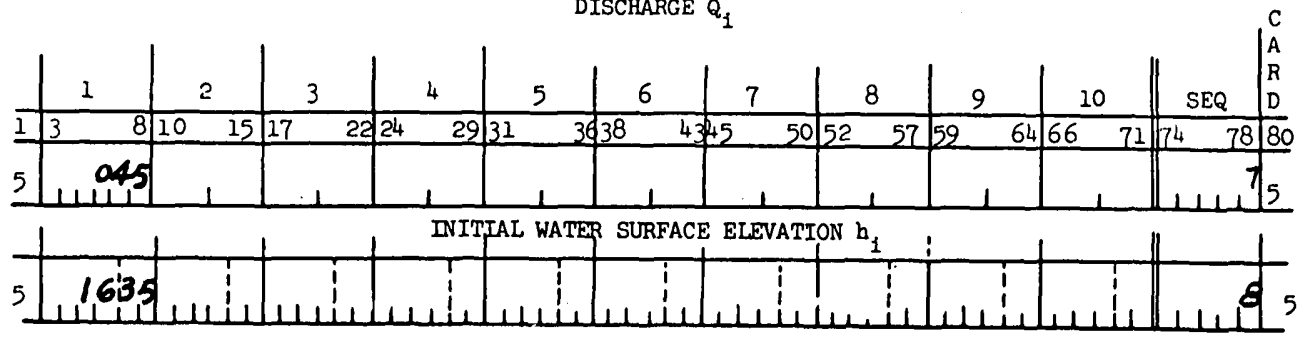

Figure 6.--Completed data form 4405A-1, cross section 1 . 


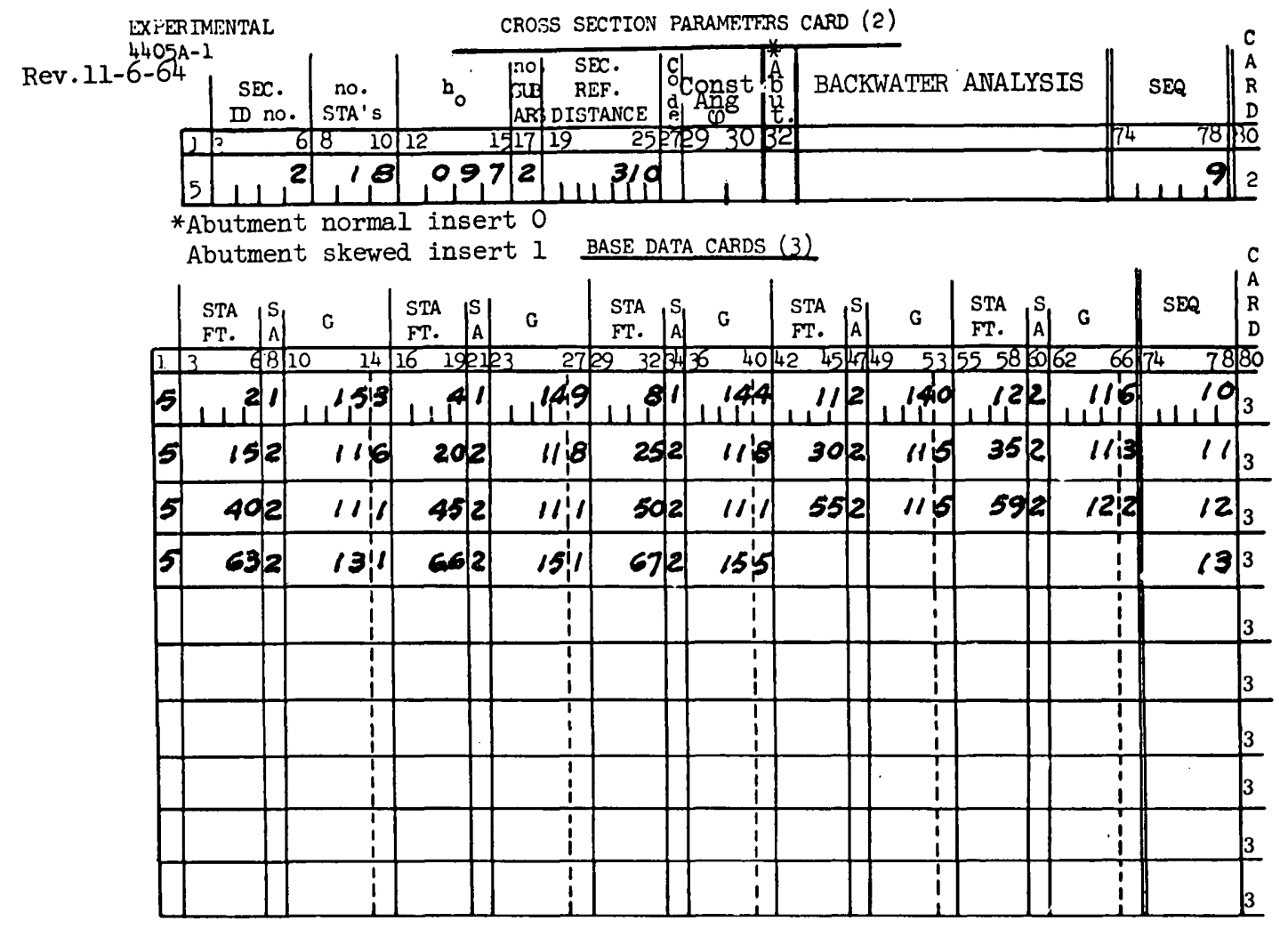

(If more than 50 stations, continue base data on second sheet)
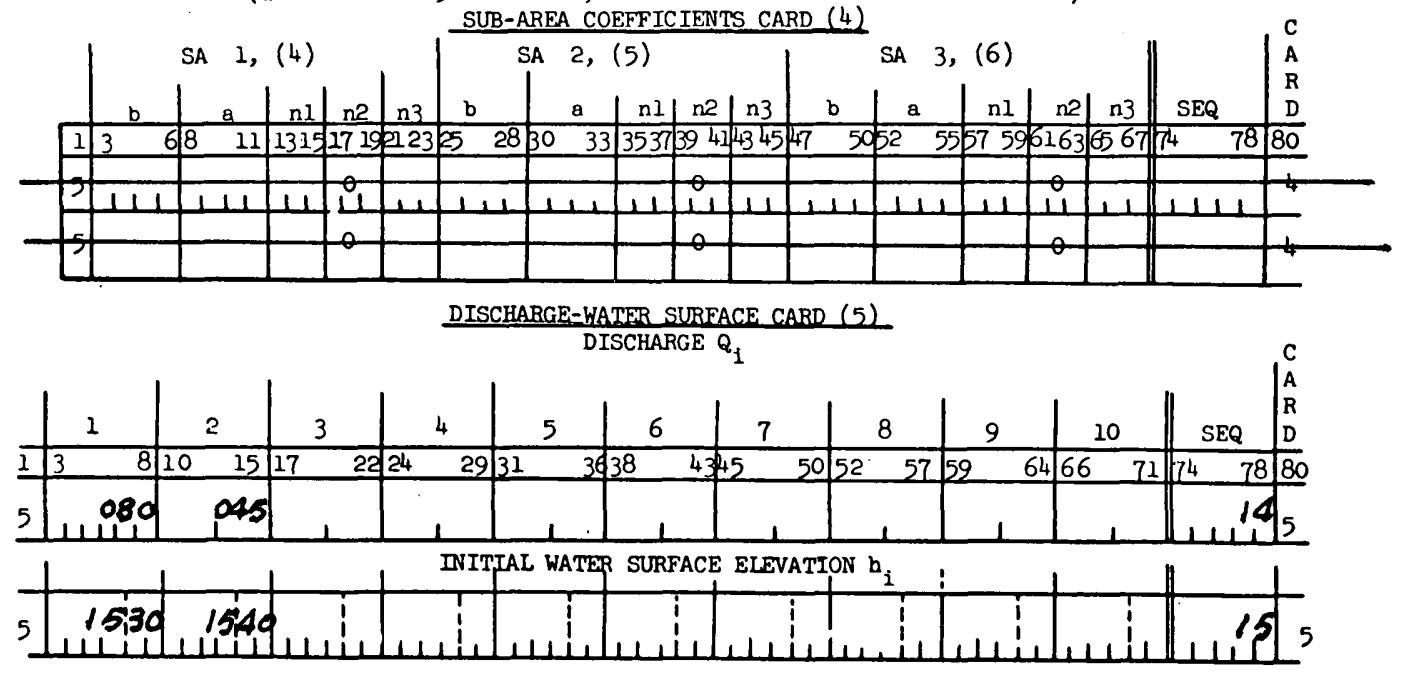

Figure 7. --Completed data form 4405A-1, cross section 2. 
EXIERTMENTAL

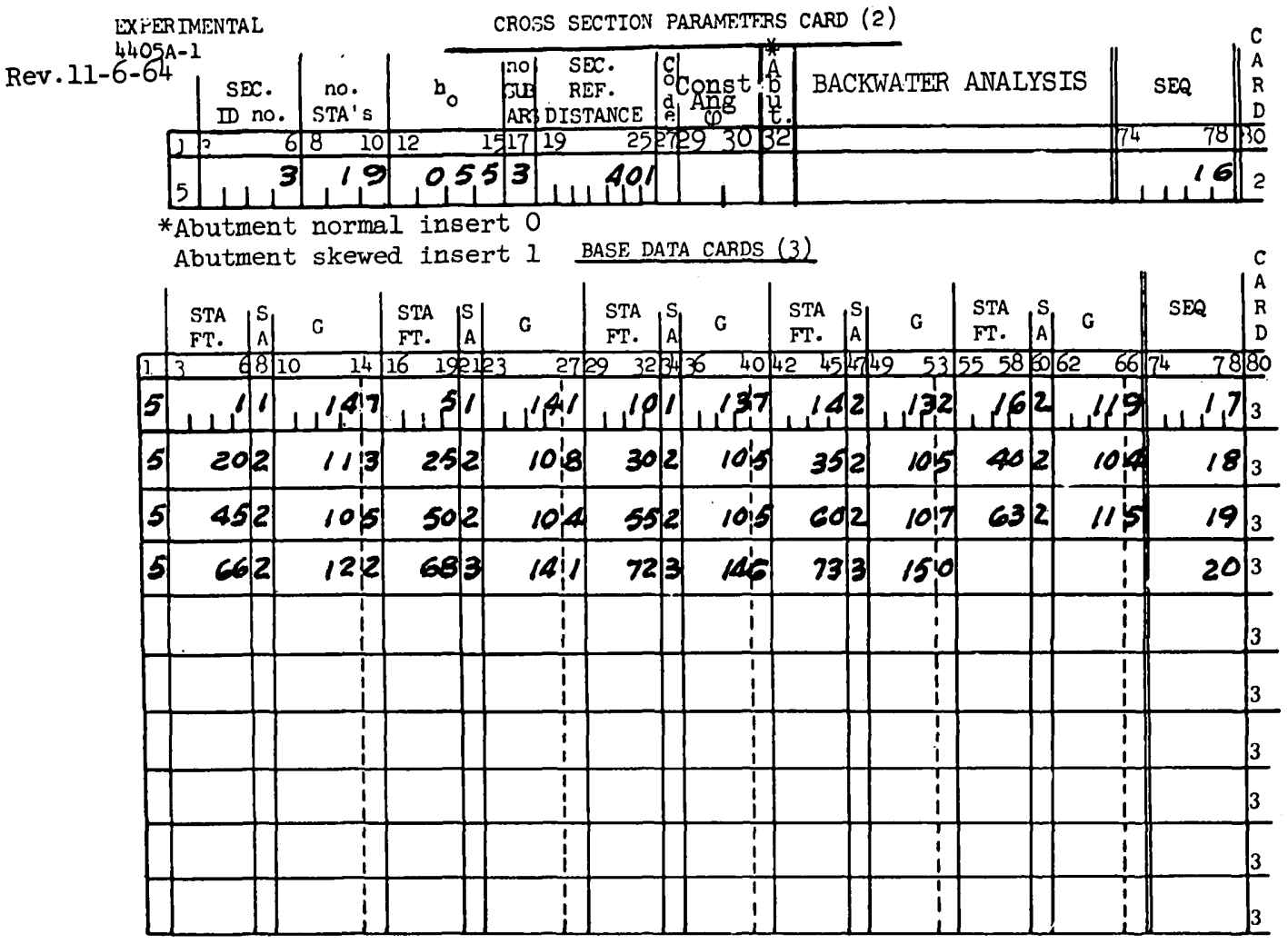

(If more than 50 stations, continue base data on second sheet)

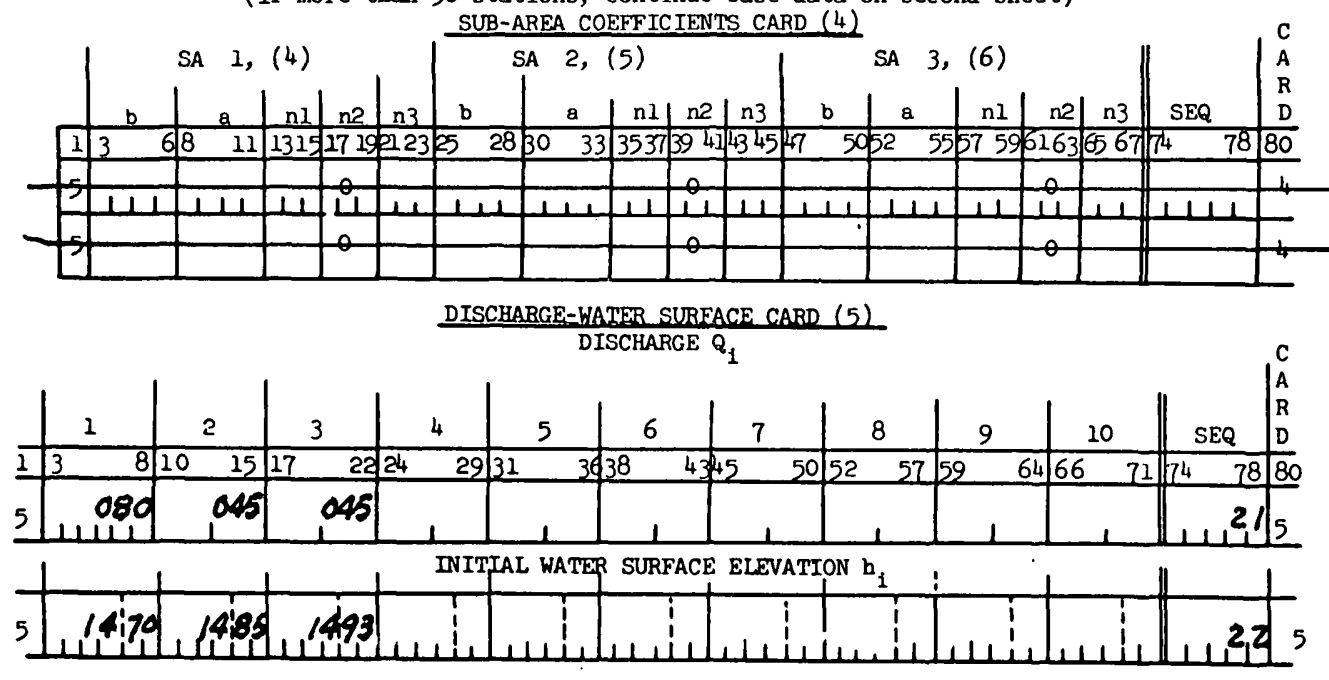

Figure 8. --Completed data form 4405A-1, cross section 3 . 


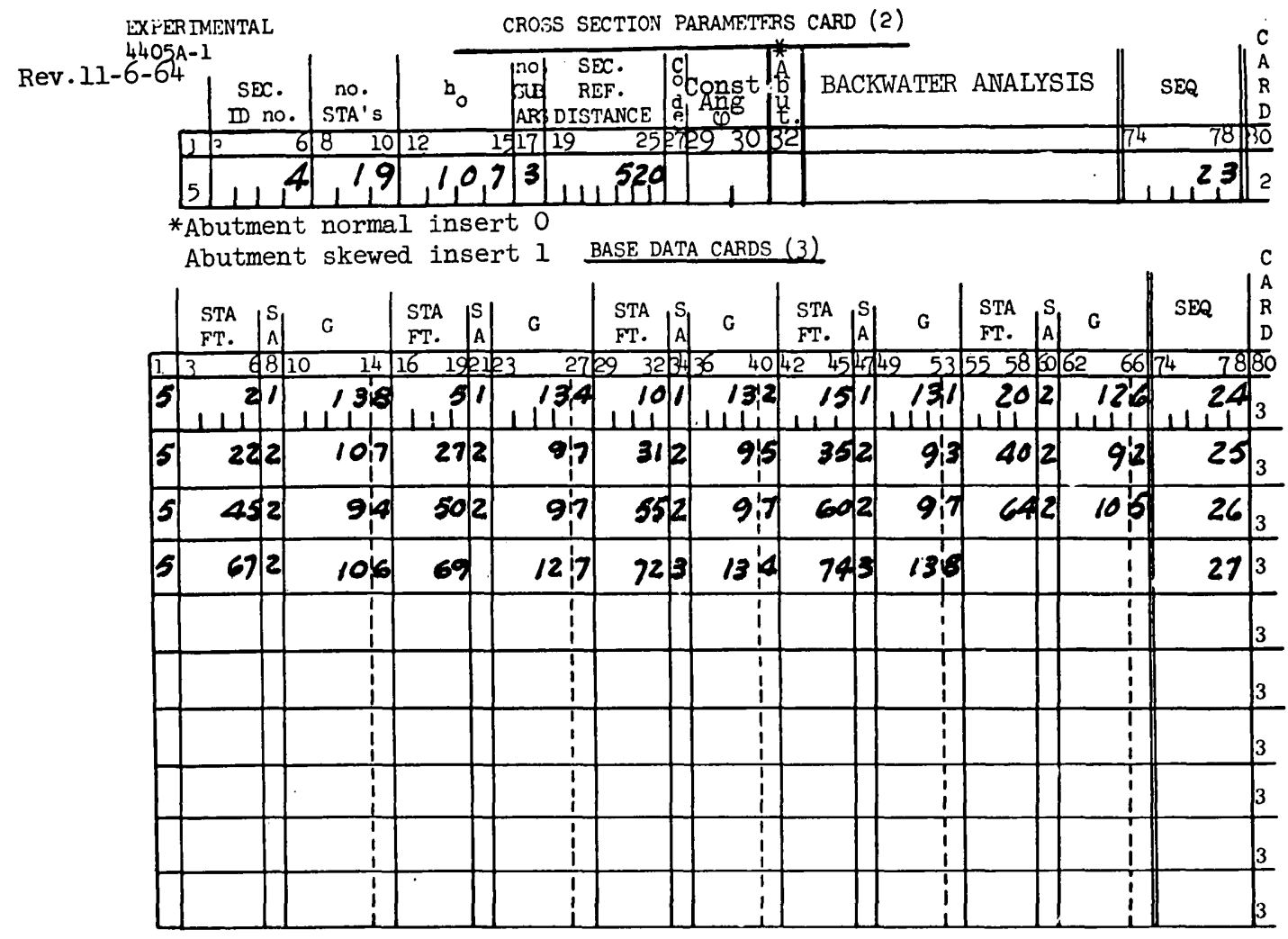

(If more than 50 stations, continue bese data on second sheet)

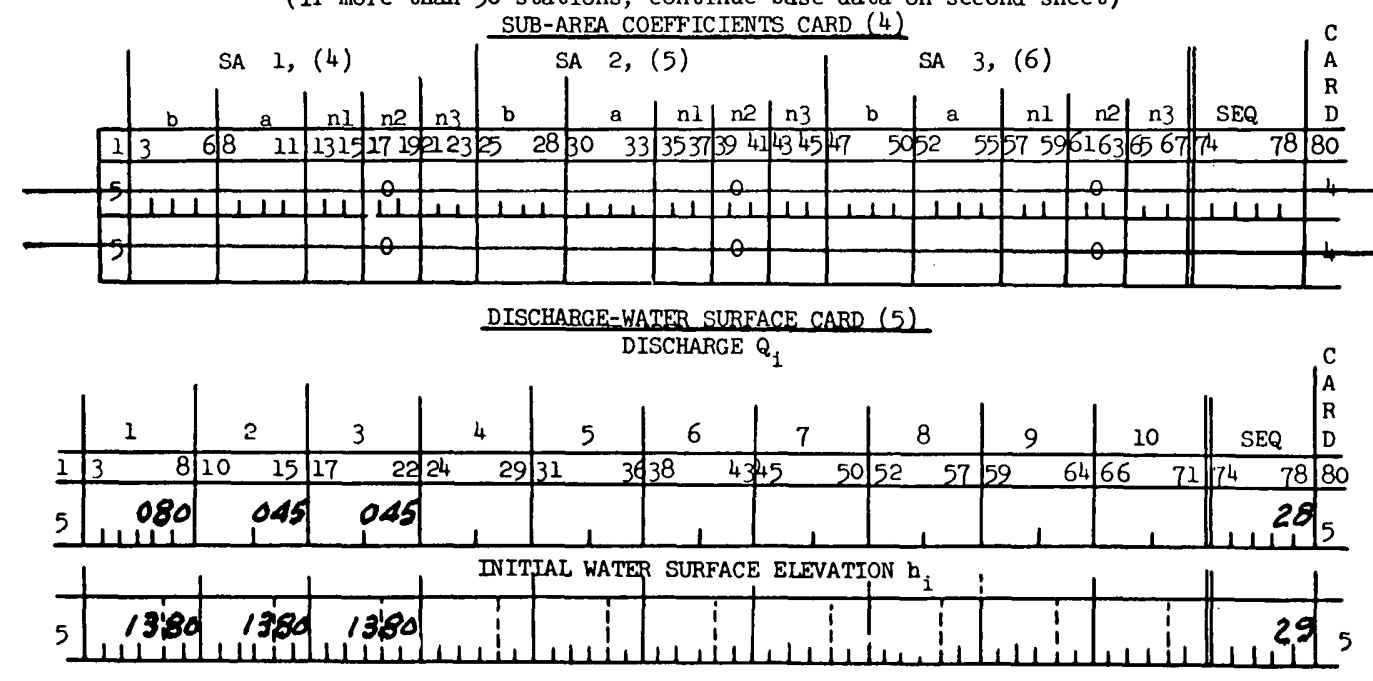

Figure 9. --Completed data form 4405A-1, cross section 4 . 
SNAKE CREEK NEAR CONNELL, WASH.

$\begin{array}{cccl}\text { DISCHARGE } & \text { BETWEEN SECTIONS } & \text { Q } \\ 0001 & - & 0002 & 1340 \\ 0002 & - & 0003 & 1330 \\ 0003 & - & 0004 & 1465\end{array}$

PROPERTIES FOR SECTION 0001

SUBAREAS

\begin{tabular}{|c|c|c|c|c|c|c|c|}
\hline & 1 & 2 & 3 & 4 & 5 & 6 & TOTAL \\
\hline AREA & 206.25 & .00 & .00 & .00 & .00 & .00 & 206.25 \\
\hline TOP WIDTH & 65.77 & .00 & .00 & .00 & .00 & .00 & 65.77 \\
\hline WETTED PERIMETER & 67. 10 & .00 & .00 & .00 & .00 & .00 & 67.10 \\
\hline HYDRAULIC RADIUS & 3.07 & .00 & .00 & .00 & .00 & .00 & \\
\hline CONVEYANCE & 14495.78 & .00 & .00 & .00 & .00 & .00 & 14495.78 \\
\hline DISCHARGE & 1385.40 & .00 & .00 & .00 & .00 & .00 & 1385.40 \\
\hline$=1.0000$ & FROUDE & E NUMBER & .6684 & & & & \\
\hline \multirow[t]{2}{*}{ PROPERTIES FOR SECTION } & 0002 & \multicolumn{6}{|c|}{ SUBAREAS } \\
\hline & 1 & 2 & 3 & 4 & 5 & 6 & TOTAL \\
\hline AREA & 6.30 & 202.96 & .00 & .00 & .00 & .00 & 209.26 \\
\hline TOP WIDTH & 9.00 & 55.75 & .00 & .00 & .00 & .00 & 64.75 \\
\hline WETTED PERIMETER & 9. 10 & 58.21 & .00 & .00 & .00 & .00 & 67.31 \\
\hline HYDRAULIC RADIUS & .69 & 3.49 & .00 & .00 & .00 & .00 & \\
\hline CONVEYANCE & 92.21 & 15514.64 & .00 & .00 & .00 & .00 & 15606.85 \\
\hline DISCHARGE & 8. 19 & 1377. 21 & .00 & .00 & .00 & .00 & 1385.40 \\
\hline ALPHA & FROUDF & E NUMBER & $=.6267$ & & & & \\
\hline \multirow[t]{2}{*}{ PROPERTIES FOR SECTION } & J 0003 & \multicolumn{6}{|c|}{ SUBAREAS } \\
\hline & 1 & 2 & 3 & 4 & 5 & 6 & TOTAL \\
\hline AREA & 10.20 & 212.25 & 2.45 & .00 & .00 & .00 & 224.90 \\
\hline TOP WIDTH & 13.00 & 54.00 & 4.83 & .00 & .00 & .00 & 71.83 \\
\hline WETTED PERIMETER & 13.09 & 55.42 & 4. 92 & .00 & .00 & .00 & 73.43 \\
\hline HYDRAULIC RADIUS & .78 & 3.83 & .50 & .00 & .00 & .00 & \\
\hline CONVEYANCE & 161.50 & 17273.27 & 51.39 & .00 & .00 & .00 & 17486.16 \\
\hline DISCHARGE & 12.80 & 1368.53 & 4.07 & .00 & .00 & .00 & 1385.40 \\
\hline$=1.0829$ & FROUDE & E NUMBER & $=.5731$ & & & & \\
\hline \multirow[t]{2}{*}{ PROPERTIES FOR SECTION } & 0004 & \multicolumn{6}{|c|}{ SUBAREAS } \\
\hline & 1 & 2 & 3 & 4 & 5 & 6 & TOTAL \\
\hline AREA & 11.10 & 193.05 & 2.65 & .00 & .00 & .00 & 206.80 \\
\hline TOP WIDTH & 18.00 & 49.00 & 5.00 & .00 & .00 & .00 & 72.00 \\
\hline WETTED PERIMETER & 18.06 & 50.86 & 5.12 & .00 & .00 & .00 & 74.04 \\
\hline HYDRAULIC RADIUS & .61 & 3.80 & .52 & .00 & .00 & .00 & \\
\hline CONVEYANCE & 150.07 & 15616.02 & 56.79 & .00 & .00 & .00 & 15822.87 \\
\hline DISCHARGE & 13.14 & 1367.28 & 4. 97 & .00 & .00 & .00 & 1385.40 \\
\hline ALPHA & FROUDF & E NUMBER & $=.6288$ & & & & \\
\hline
\end{tabular}

Figure 10.--Results of computation given on printout sheet, Snake River near Connell, Wash., flood of February 21, 1956. 


\section{REFERENCES}

Dalirymple, Tate, and Benson, M. A., 1965, Measurement of peak discharge by the slope-are method: Surface Water Techniques, Book 1, Chapter 4, U.S. Geol. Survey report (in preparation).
Selner, G. I., 1965, Slope-area solution for discharge: U.S. Geol. Survey Burroughs 220 computer documentation, Job No. 4444 (written communication). 